\title{
Protection and Response of a Tertiary Hospital in South Korea to the COVID-19 Outbreak
}

Hye Jin Shi, MD; Jae Back Lee, MSc; Min Kyung Choi, MSc; Young-Rock Jang, MD; Yong-Kyun Cho, MD, PhD; Joong Sik Eom, MD, PhD

\section{ABSTRACT}

Objective: Here, we present an overview of how a tertiary hospital responded to maintain necessary activities and protect patients and staff from the coronavirus disease (COVID-19) outbreak.

Methods: Gil Medical Center, a tertiary hospital in Incheon, has operated a special response team since January 21, 2020. All visitors were assessed for body temperature and respiratory symptoms, and screened for recent overseas travel. Suspected COVID-19 patients were taken to a screening clinic. All febrile patients with or without respiratory symptoms were taken to a respiratory safety clinic. An isolation ward, which consisted of 10 negative-pressure rooms, was used to treat confirmed cases. More than 120 beds were prepared for the outbreak, and patients with pneumonia were preemptively isolated.

Results: By May 5, 480960 visitors were assessed at the control station, 3350 patients visited the triage center, and 1794 were treated in the respiratory safety clinic. Seventeen confirmed cases were admitted to the negative isolation ward, and 350 patients with pneumonia were preemptively isolated. A total of 2977 severe acute respiratory syndrome coronavirus 2 (SARS-CoV-2) polymerase chain reaction tests were performed.

Conclusions: While tertiary hospitals play an important role in treating both COVID-19 patients and nonCOVID-19 patients, hospital staff have to protect themselves from unexpected in-hospital transmission. A multifaceted response must be undertaken to protect tertiary hospitals and their staff during the COVID-19 epidemic.

Key Words: COVID-19, protection, response, South Korea, tertiary hospital

O evere acute respiratory syndrome coronavirus 2 (SARS-CoV-2), the virus that causes coronavirus disease (COVID-19), had a global impact, and the World Health Organization (WHO) declared the disease a pandemic. ${ }^{1}$ By May 5, 2020, there were 3 517345 laboratory confirmed-cases, but Korea had only 10806 confirmed cases, despite large test numbers. ${ }^{2,3}$ The world had a lot of questions about how Korea controlled its COVID-19 outbreak. ${ }^{4}$

During the epidemic, tertiary hospitals in Korea screened cases, isolated patients, and treated confirmed severe cases. Gil Medical Center (GMC) is a 1450-bed, tertiary care hospital in Incheon, Republic of Korea, and operates with unique surveillance and isolation systems for COVID-19. As a result of these efforts, the hospital experienced no outbreaks and continued to function effectively over the 3 month course of the COVID-19 epidemic. We describe our response and protective strategies for controlling the epidemic in a Korean tertiary care hospital with regard to the timeline of the outbreak, with the aim of providing recommendations for controlling future COVID-19 epidemics.

\section{METHODS}

We used all records created during the outbreak, including patients' contact investigation records, monitoring records for all admitted suspected or confirmed cases, results of daily SARS-CoV-2 polymerase chain reaction (PCR) assays, and the number of triage center outpatients, quarantined persons, and COVID-19 cases from January 21 to May 5, 2020. Various control measures were implemented in response to the critical events specific to each phase of the epidemic. This study was approved by the institutional review board of the GMC.

\section{Changes in COVID-19 Case Definition}

The Korea Center for Disease Control (KCDC) provides definitions of COVID-19 confirmed cases, suspected cases, and patients under investigation (PUI). From January 21 to March 2, the KCDC made 4 major changes to the definition of suspected cases and PUI to apply epidemiologic change.

\section{Isolation Ward}

The GMC had 1 isolation ward, with 10 negative-pressured rooms. It was a nationally designated isolation 
ward and controlled by government and GMC infection specialist co-operations. After receiving a declaration of suspected cases or confirmed cases (ie, from airport quarantine or a general hospital), the local government made transfer requests to GMC. The suspected case was transferred to GMC through a negative-pressure ambulance and an independent elevator directly to the isolation ward from outside. GMC infectious disease specialists wearing personal protective equipment (PPE) examined admitted patients and performed tests for SARS-CoV-2 and chest radiography (ie, CXR).

\section{Triage Center and Respiratory Safety Clinic}

GMC began operating as an independent triage center on January 26, 2020. Outpatients and visitors to the emergency department (ED) with epidemiologic links or with respiratory symptoms were treated at the triage center. The first triage center was located at the ED and consisted of 1 clinic, 1 radiography room, 2 sample collection rooms, and 1 waiting room, all of which were negatively pressurized and separated from other ED spaces. After a large outbreak occurred at February 24, we expanded the respiratory safety clinic at a separate building and established 6 negative-pressure offices.

\section{Entrance Control Station}

GMC had 43 entrances, and it was impossible to monitor all of the entrances. We blocked all entrances except for the 10 entrances and installed control stations. Security staff, nurses, and health care workers (HCWs) in other service departments were equipped with PPE and stationed at the entrances to check all hospital visitors, including patients, HCWs, caregivers, visitors, and suppliers, for symptoms and epidemiologic risks.

\section{HCW Monitoring and Work Restrictions}

Community transmission began in Korea on February 18, and we performed contact tracing for our HCWs. We assessed for visits to danger zones within the previous 2 weeks, possible contact with confirmed cases, and the presence of symptoms. ${ }^{5,6}$ If an HCW developed symptoms with an epidemiologic link, that individual was immediately placed under work restrictions until a negative result for SARS-CoV-2 was obtained.

\section{RESULTS}

\section{Changes in COVID-19 Case Definition}

As defined by the KCDC, confirmed cases were those with the presence of infectious pathogens regardless of clinical presentation; this definition did not change during the study period. Suspected cases were first restricted to visitors of Wuhan city who had symptoms, but the epidemiology changed and the spectrum of suspected cases also expanded to include patients who developed a fever $\left(>37.5^{\circ} \mathrm{C}\right)$ or respiratory symptoms (eg, cough, dyspnea, sore throat) within 14 days of contact with a confirmed patient during the period of symptomatic manifestation. The definition of PUI changed most dramatically, from pneumonia with a history of visiting China to solely pneumonia (Table 1).

Regions of local transmission (danger zones) were the key to case definitions in GMC. Before February 7, the danger zone was limited to the city of Wuhan and Hubei Province, China. After February 7, when an epidemic outside of China was reported, GMC updated our danger zone daily according to the WHO situation report. After February 18, when the Daegu city, Gyeongsangbuk Province, and Shincheonji (religious group) outbreaks occurred in South Korea, GMC rapidly expanded the danger zone to Daegu city and involvement with Shincheonji. After March 8, when Seoul and the metropolitan area were in danger, we put less emphasis on geography and more on symptoms and contact with confirmed cases.

\section{Isolation Wards}

On February 24, the first confirmed case (a 70-year-old man diagnosed for COVID-19 at a nursing hospital in Gyeongsangbuk Province) was transferred to GMC due to the lack of an isolation room in the local area. We have 1 isolation ward, but it was vital to separate confirmed cases from suspected cases or PUI. Hospital management decided to empty 1 floor for suspected cases. A 46-bed ward with portable negative-pressure devices was opened on February 28, and suspected cases or PUI from the triage center or outpatient clinic were admitted to this ward.

By May 5, 17 confirmed cases with 5 recovered cases (Table 2) had been admitted to the isolation ward. A total of 350 suspected cases or PUI were admitted to the second isolation ward, with no confirmed cases among them.

\section{Triage Center}

On January 26, the triage center was built within the ED. A nurse wearing PPE took a simple history of the patient and reception was made by telephone. During each visit, the patient's epidemiologic risk factors and symptoms were recorded. A doctor with PPE examined the patient, and a CXR was performed in all patients. If a suspected case or PUI required admission, the patient was placed in the isolation ward. By May 5, 3350 patients visited the triage center, and 1 patient was confirmed to have COVID-19. However, no further exposure occurred because of complete separation of the areas and hygiene protocols.

\section{Respiratory Safety Clinic}

As local transmission in Korea became a reality and large hospitals were shut down, we tried to be especially careful about separating suspected cases and PUI from other patients. We opened the respiratory safety clinic at a different building on February 24. Patients with any symptoms had mandatory assessments at the respiratory safety clinic or triage center 


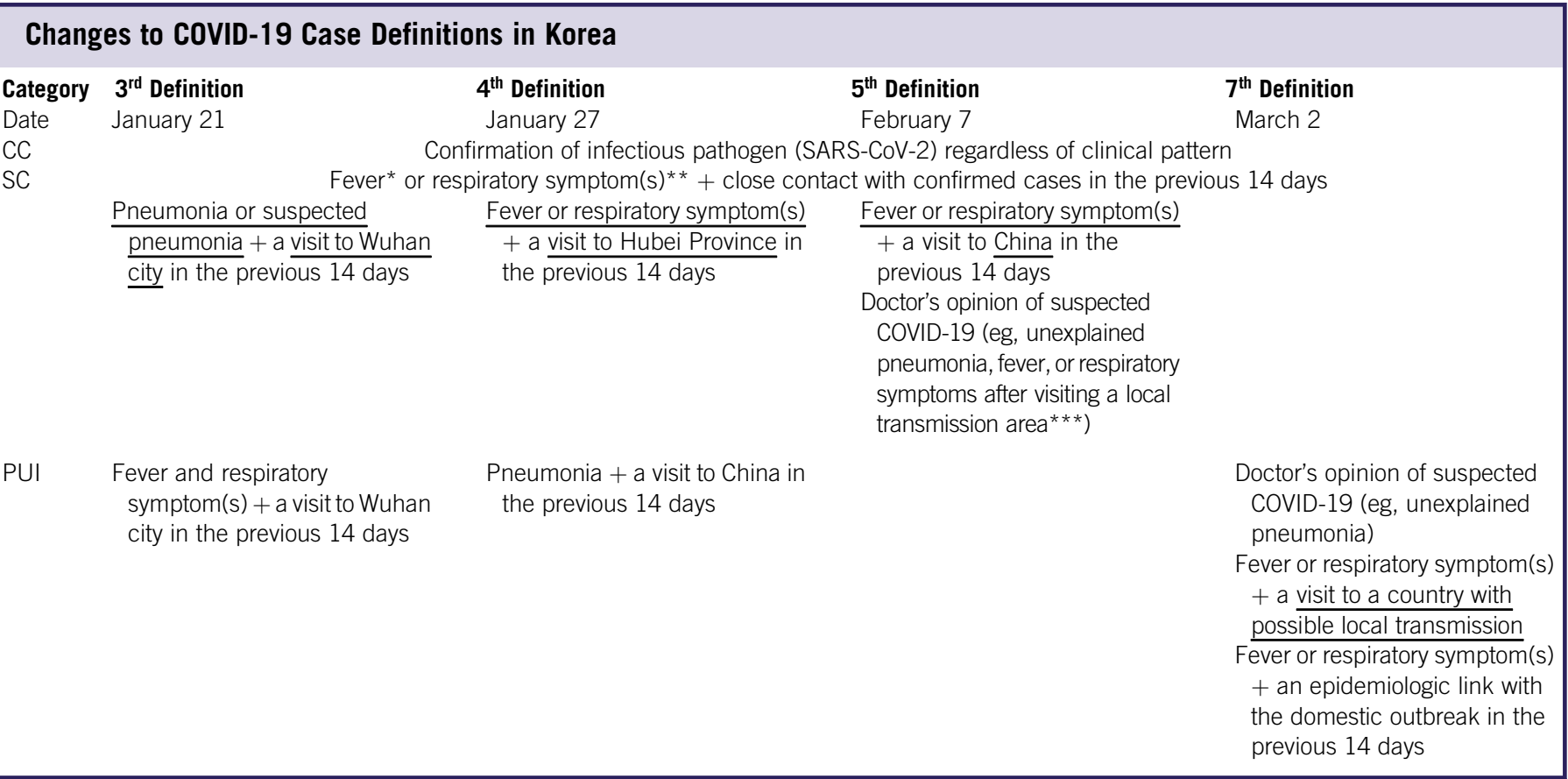

Notes: $*$ fever $=$ body temperature over $37.5^{\circ} \mathrm{C} ; * *$ respiratory symptom $(\mathrm{s})=$ cough, dyspnea, sputum, sore throat, etc.; $* * *$ local transmission area $=$ updated daily by the World Health Organization (WHO); CC = confirmed cases; SC = suspected cases; $\mathrm{PUI}=$ patient under investigation; SARS-CoV-2 = severe acute respiratory syndrome coronavirus 2; COVID-19 = coronavirus disease 2019.

before they reached the hospital. The triage protocol here was identical to that of the triage center. By May 5, 1794 patients had been treated in the safety clinic.

\section{Entrance Control Station}

$\mathrm{HCW}$ s at 10 control stations screened visitors for symptoms (eg, fever, respiratory symptoms), recent visits to danger zones, history of contact with confirmed cases, and the purpose of their visit. The national drug utilization review temporarily provides information on visits to danger zones (countries in which local transmission occurred), making it possible to double check. All unnecessary visitations were rejected.

People with symptoms or a history of visits to risky areas were referred to the triage center via an outside pathway by security staff wearing PPE. By May 5, 480960 people were assessed at the control station, and no unprotected exposures to confirmed cases or suspected cases occurred at GMC.

\section{Number of SARS-CoV-2 Tests}

From January 21 to February 7, only 27 tests were performed at the GMC. Before February 7, real-time PCR kits for testing for SARS-CoV-2 were only available through the KCDC, and doctors could not perform this test without government permission. After February 7, the SARS-CoV-2 testing was expanded to private medical institutions. A total of 2977 tests were performed at the GMC by May 5 .

\section{Personal Protective Equipment}

Owing to the unknown pathophysiology of the disease, at first, all HCWs at the triage center or isolation wards wore headcovering coveralls (level D) and a powered air-purifying respirator (PAPR). HCWs working at the control center wore 5-piece protection (ie, gown, gloves, N-95 mask, goggles or face shield, hair cap).

After February 18, the Daegu area experienced a critical shortage of equipment, and country-level downsizing of PPE was required. After March 8, we downgraded our hospital PPE level. Only HCWs dealing with confirmed cases wore level D protection and a PAPR. HCWs working at the triage center or at the control center wore 5-piece protection.

\section{HCW Monitoring and Work Restrictions}

After March 8, when transmission in the metropolitan area occurred, $14 \mathrm{HCW}$ s were monitored. They all tested negative, and $1 \mathrm{HCW}$ who had visited the Daegu area was placed under work restrictions because of persistent symptoms.

\section{DISCUSSION}

Tertiary hospitals in Korea had to play a vital role in managing the COVID-19 epidemic. They take the lead in both accepting confirmed cases and handling primarily suspected cases during outbreaks. At the same time, they had to play a primary role with treating severe, critically ill patients (including the 
TABLE 2

\section{Epidemiologic Information About Confirmed Cases Admitted to GMC}

\begin{tabular}{|c|c|c|c|c|c|c|c|c|c|c|c|}
\hline $\mathbf{N}$ & Age/Sex & Nationality & Confirmed Date & Location & Source of Infection & Initial Severity & Admission Date & Discharge Date & $\begin{array}{l}\text { Underlying } \\
\text { Disease(s) }\end{array}$ & Clinical Outcome & $\begin{array}{l}\text { Latest } \\
\text { RT-PCR }\end{array}$ \\
\hline 1 & 70/M & Korea & 21 February & Daegu & $\begin{array}{l}\text { Nursing hospital } \\
\text { outbreak }\end{array}$ & Moderate & 24 February & 16 March & Schizophrenia & $\begin{array}{l}\text { Symptoms } \\
\text { relieved }\end{array}$ & $\begin{array}{l}\text { Negative } \\
\text { (2 times) }\end{array}$ \\
\hline 2 & $56 / M$ & Korea & 24 February & Daegu & Shincheonji & Mild & 28 February & 28 March & CKD on $\mathrm{HD}$ & $\begin{array}{l}\text { Symptoms } \\
\text { relieved }\end{array}$ & $\begin{array}{l}\text { Negative } \\
\quad(2 \text { times) }\end{array}$ \\
\hline 3 & $76 / \mathrm{M}$ & Korea & 28 February & Gimcheon & $\begin{array}{l}\text { Close contact with } \\
\text { confirmed case }\end{array}$ & Very severe & 01 March & 01 April & $\begin{array}{l}\text { Prostate cancer, } \\
\text { diabetes mellitus }\end{array}$ & $\begin{array}{l}\text { Symptoms } \\
\text { relieved }\end{array}$ & $\begin{array}{l}\text { Negative } \\
\text { (2 times) }\end{array}$ \\
\hline 4 & $70 / F$ & Korea & 20 February & Sangju & $\begin{array}{l}\text { Nursing hospital } \\
\text { outbreak }\end{array}$ & Severe & 04 March & TBD & Dementia & $\begin{array}{l}\text { On ventilator, } \\
\text { CRRT }\end{array}$ & $\begin{array}{l}\text { Negative } \\
\text { (2 times) }\end{array}$ \\
\hline 5 & $50 / M$ & Korea & 06 March & Incheon & $\begin{array}{l}\text { Nursing hospital } \\
\text { outbreak }\end{array}$ & Asymptomatic & 06 March & TBD & None & Asymptomatic & $\begin{array}{l}\text { Negative } \\
\quad \text { (1 times) }\end{array}$ \\
\hline 6 & $93 / F$ & Korea & 08 March & Andong & Shincheonji & Severe & 09 March & 31 March & Dementia & $\begin{array}{l}\text { Symptoms } \\
\text { relieved }\end{array}$ & $\begin{array}{l}\text { Negative } \\
\quad \text { (2 times) }\end{array}$ \\
\hline 7 & $38 / F$ & Korea & 14 March & Incheon & $\begin{array}{c}\text { Telephone } \\
\text { marketing } \\
\text { outbreak }\end{array}$ & Mild & 14 March & TBD & None & $\begin{array}{l}\text { Symptoms } \\
\text { relived }\end{array}$ & Positive \\
\hline 8 & $49 / M$ & Philippines & 20 March & Airport & Imported & Mild & 20 March & TBD & None & $\begin{array}{l}\text { On ventilator, } \\
\text { ECMO, CRRT }\end{array}$ & $\begin{array}{l}\text { Negative } \\
\quad \text { (1 times) }\end{array}$ \\
\hline 9 & $56 / F$ & Korea & 28 March & Airport & Imported & Asymptomatic & 28 March & TBD & None & Asymptomatic & Positive \\
\hline 10 & $47 / F$ & Korea & 28 March & Incheon & $\begin{array}{l}\text { Close contact with } \\
\text { confirmed case }\end{array}$ & Asymptomatic & 28 March & TBD & None & Asymptomatic & Positive \\
\hline 11 & $76 / \mathrm{M}$ & U.S. & 30 March & Incheon & Imported & Mild & 30 March & TBD & Prostate cancer & $\begin{array}{l}\text { Symptoms } \\
\text { relieved }\end{array}$ & Positive \\
\hline 12 & $47 / F$ & Philippines & 1 April & Incheon & $\begin{array}{l}\text { Close contact with } \\
\text { confirmed case }\end{array}$ & Asymptomatic & 1 April & TBD & None & Asymptomatic & Positive \\
\hline 13 & $7 / F$ & Philippines & 1 April & Incheon & $\begin{array}{l}\text { Close contact with } \\
\text { confirmed case }\end{array}$ & Asymptomatic & 1 April & TBD & None & Asymptomatic & Positive \\
\hline 14 & $67 / F$ & Korea & 1 April & Incheon & $\begin{array}{l}\text { Close contact with } \\
\text { confirmed case }\end{array}$ & Mild & 1 April & 25 April & Hypertension & $\begin{array}{l}\text { Symptoms } \\
\text { relieved }\end{array}$ & 2 Negative \\
\hline 15 & 70/M & Korea & 4 April & Incheon & Imported & Asymptomatic & 4 April & TBD & COPD & Asymptomatic & Positive \\
\hline 16 & $67 / F$ & Korea & 9 April & Seoul & Imported & Asymptomatic & 9 April & TBD & Hypertension & Asymptomatic & 1 Negative \\
\hline 17 & $82 / \mathrm{M}$ & Korea & 29 April & Incheon & Imported & Very severe & 29 April & TBD & $\begin{array}{l}\text { Atrial fibrillation, } \\
\text { hypertension }\end{array}$ & $\begin{array}{l}\text { On high dose } \\
\text { O2 inhalation }\end{array}$ & Positive \\
\hline
\end{tabular}

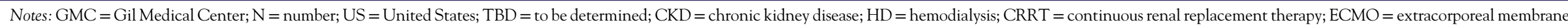

oxygenation; RT-PCR = reverse transcription polymerase chain reaction; $\mathrm{COPD}=$ chronic obstructive pulmonary disease. 
immune-suppressed), as well as quarantine gate their local regions, screening all pneumonia patients. The exposure to unscreened patients in hospitals posed many problems, specifically the additional propagation of the disease by causing mass outbreaks in high-risk patients ${ }^{7,8}$ and exposing HCWs to risk. When in-hospital exposure occurs, hospitals cannot function effectively, and it is impossible to conduct necessary medical treatments. In Korea, some hospitals had to close temporarily because of in-hospital transmission of COVID-19. ${ }^{9}$

Hospital protection may need multiple strategies simultaneously. In almost every case, especially during an epidemic or pandemic, dealing with a newly emerging infectious disease is very challenging because of lack of experience, knowledge, and preparation. We wanted to share our experiences because our situation is similar or perhaps more serious than in other countries suffering from COVID-19.

Based on our experience, changing both the targets and strategies based on the degree of local transmission is a key control measure in the COVID-19 epidemic. When local transmission in Incheon was uncommon, additional non-targeted screening measures, including symptom monitoring and CXR screening, did not detect additional patients with COVID-19 without epidemiologic links. In addition, quarantine played an important role, and defining an accurate epidemiologic danger zone and assessing for epidemiologic links were key components to finding additional patients. We expanded or narrowed the definition of suspected cases and PUI using up-to-date information from the KCDC.

Total isolation of the pathways taken by PUI was also a key component. COVID-19 patients are often indistinguishable from non-patients based on symptoms or CXRs because of the highly contagious nature and nonspecific symptoms of COVID-19. ${ }^{7,10}$ During the epidemic, we operated a ward only for suspected cases or PUI, so that we could almost completely separate these cases from other inpatients. Though there was only 1 confirmed case out of 3300 triage visits, the vital role of the triage center was to reduce exposures to COVID-19 within the hospital. Total separation of pathways taken by PUI and non-patients was also helpful during contact investigations. Two potential exposures occurred during the study period. However, there were no further exposures in either 2 cases, and we did not need to perform contact tracing inside our hospital. Pathway separation was especially important during active local transmission, when the number of patients increased and it was necessary to guard against massive local transmission.

\section{CONCLUSION}

In conclusion, hospitals and their staff have to concentrate on protecting themselves from unexpected in-hospital transmission during the COVID-19 epidemic. The changing of target individuals with epidemiologic links according to the degree of local transmission, operating the triage center, controlling hospital entry, preparing capacity to isolation, and adjusting the level of quarantine and PPE according to the expected degree of local transmission were all strongly important to protect hospitals and countries during the COVID-19 pandemic.

\section{About the Authors}

Division of Infectious Diseases, Department of Internal Medicine, Gil Medical Center, Gachon University School of Medicine, Incheon, Republic of Korea (Drs Shi, Jang, Cho, Eom) and Unit of Infection Control, Gil Medical Center, Gachon University School of Medicine, Incheon, Republic of Korea (Ms Lee, Ms Choi).

Correspondence and reprint requests to Joong Sik Eom, Division of Infectious Diseases, Department of Internal Medicine, Gil Medical Center, Gachon University School of Medicine, 774 Beon-gil 21, Namdong-gu, Incheon 21565, Republic of Korea (e-mail: helppl@gachon.ac.kr)

\section{Ethical Approval}

This study was approved by our hospital institutional review board (IRB number: GRIRB2020-164).

\section{Conflict of Interest Statement}

The authors have no conflicts of interest to declare.

\section{References}

1. Kluge HHP. WHO announces COVID-19 outbreak a pandemic. 2020. http://www.euro.who.int/en/health-topics/health-emergencies/coronaviruscovid-19/news/news/2020/3/who-announces-covid-19-outbreak-a-pandemic. Accessed March 12, 2020

2. World Health Organization. Coronavirus disease (COVID-19) situation report-106. May 5, 2020. https://www.who.int/docs/default-source/ coronaviruse/situation-reports/20200505 covid-19-sitrep-106.pdf?sfvrsn= 47090f63_2. Accessed May 6, 2020.

3. MOHW. Trends in development. Domestic outbreak (KCDC) KCoD. COVID-19-Korean situation report. 2020. http://ncov.mohw.go.kr/ bdBoardList_Real.do?brdId=1\&brdGubun=11\&ncvContSeq=\&contSeq= \&board_id=\&gubun=. Accessed May 6, 2020.

4. Bicker L. Coronavirus in South Korea: how "trace, test and treat" may be saving lives. BBC News. March 12, 2020. https://www.bbc.com/news/ world-asia-51836898. Accessed May 6, 2020.

5. Liu Z, Bing X, Zhi XZ. The epidemiological characteristics of an outbreak of 2019 novel coronavirus diseases (COVID-19) in China. Chin J Epidemiol. 2020;41(2):145-151.

6. Zu ZY, Jiang MD, Xu PP, et al. Coronavirus disease 2019 (COVID-19): a perspective from China. Radiology. 2020;epub:200490.

7. Lake MA. What we know so far: COVID-19 current clinical knowledge and research. Clin Med (Lond). 2020;20(2):124-127.

8. Lim J, Jeon S, Shin HY, et al. Case of the index patient who caused tertiary transmission of COVID-19 infection in Korea: the application of lopinavir/ritonavir for the treatment of COVID-19 infected pneumonia monitored by quantitative RT-PCR. J Korean Med Sci. 2020;35(6):e79.

9. Lee H, Heo JW, Kim SW, Lee J, Choi JH. A lesson from temporary closing of a single university-affiliated hospital owing to in-hospital transmission of coronavirus disease 2019. J Korean Med Sci. 2020;35(13):e145.

10. Liu Y, Gayle AA, Wilder-Smith A, Rocklöv J. The reproductive number of COVID-19 is higher compared to SARS coronavirus. J Travel Med. 2020;27(2):taaa021. 